Article

\title{
Synthesis, Modification and Characterization of Antimicrobial Textile Surface Containing ZnO Nanoparticles
}

\author{
L. Martinaga Pintarić ${ }^{1}\left(\mathbb{D}\right.$, M. Somogi Škoc ${ }^{1} \mathbb{D}$, V. Ljoljić Bilić ${ }^{2} \mathbb{D}$, I. Pokrovac $^{2}$, I. Kosalec ${ }^{2} \mathbb{D}$ and \\ I. Rezić ${ }^{1, *(D)}$ \\ 1 Faculty of Textile Technology, Department of Applied Chemistry, University of Zagreb, 10000 Zagreb, \\ Croatia; lela.pintaric@ttf.hr (L.M.P.); maja.somogyi@ttf.hr (M.S.Š.) \\ 2 Faculty of Pharmacy and Biochemistry, University of Zagreb, 10000 Zagreb, Croatia; \\ vljoljic@pharma.hr (V.L.B.); ivan.pokrovac.fbf@gmail.com (I.P.); ikosalec@pharma.hr (I.K.) \\ * Correspondence: iva.rezic@ttf.hr or iva_rezic@net.hr
}

Received: 30 April 2020; Accepted: 22 May 2020; Published: 26 May 2020

check for updates

\begin{abstract}
In this research, a textile surface was modified by the sol-gel methodology with a new antimicrobial coating containing nanoparticles active against bacteria resistant to antibiotics. The effect of ultrasonic irradiation power (40 to $90 \mathrm{kHz}$ ), the concentration of reagents (nanoparticles, precursor and acids) and time (15 to $72 \mathrm{~min}$ ) were investigated in relation to the structure, morphology and antimicrobial activity of coatings with zinc oxide nanoparticles. The relationship between the sonocatalytic performance and structure of the resultant modification was established by using various techniques, such as FTIR spectroscopy (FTIR) and scanning electron microscopy with an EDX detector (SEM-EDX), thin-layer chromatography (TLC) and antimicrobial effects were determined on selected model microorganisms. The homogeneity of layers with $\mathrm{ZnO}$ nanoparticles on samples was increased by increasing the ultrasonic irradiation power and time. The ultrasonic irradiation unify did not only unify both the structure and the morphology of samples, it also prevented the agglomeration of the nanoparticles. Moreover, under optimal conditions, an antimicrobial coating with $\mathrm{ZnO}$ nanoparticles, active against bacterial species $S$. aureus and E. coli was efficiently prepared. Results of the Time-kill methodology revieled excellent results starting after 6 hours of exposal to antimicrobialy functionalized cellulose polymer.
\end{abstract}

Keywords: nanoparticles; coating; antibacterial resistance; antimicrobial activity; ZnO; optimization

\section{Introduction}

According to some predictions, by 2050, more people could die from the infections caused by antibiotic-resistant bacteria than from cancer. In Europe 25,000 deaths per year and costs over EUR 1.5 billion are associated with resistant microorganisms [1]. In particular, dangerous infections include bacteria such as methicillin-resistant Staphylococcus aureus (MRSA), known as a "super-bacteria", which is increasingly difficult to cope with due to its resistance to a wide range of antibiotic-based penicillin drugs ( $\beta$-lactam antibiotics such as penams and cephalosporins). Staphylococcus aureus is a member of the Staphylococcaceae family of Gram-positive bacteria spherical forms and is one of the most significant pathogens in the world. It is an infection with a frequency ranging from 20 to 50 cases per 100,000 inhabitants per year, with 10 to 30\% of infections ending with a deadly outcome. This number is greater than the sum of the deaths caused by Acquired Immunodeficiency Syndrome (AIDS), tuberculosis and viral hepatitis combined [2].

Metal oxide nanoparticles provide excellent antimicrobial, water resistance and protective properties. Among them, $\mathrm{ZnO}$ nanoparticles are one of the most important antimicrobial reagents. 
Therefore, cellulose materials with $\mathrm{ZnO}$ nanoparticles coatings can be found in different protective materials. The extraordinary antimicrobial activity of $\mathrm{ZnO}$ nanoparticles, which receives significant global interest, is the result of very small diameters of nanoparticles, which are far below the range of the microorganisms' dimensions. Recent investigations have shown that nanosized $\mathrm{ZnO}$ can interact with both bacterial surfaces and/or with the bacterial cells, after it enters through the membrane [3]. $\mathrm{ZnO}$ nanoparticles showed antimicrobial activity on different microorganisms, including Gram-positive and Gram-negative bacteria, as well as on spores that are resistant to high temperature and high pressure [4].

In contrast to their significant antimicrobial effects, nanoparticles made of $\mathrm{ZnO}$ were found to be non-toxic to human cells. Moreover, their biocompatibility with human cells was proven in the investigation of Padmavathy and Vijayaraghavan [5]. The safety of $\mathrm{ZnO}$ and its compatibility with human skin make it a suitable additive for textiles and surfaces that are exposed to the human body [6,7]. This makes them significant potential antimicrobial agents that need to be explored. Currently, such investigations are in progress. $\mathrm{ZnO}$ nanoparticles show activity over a wide spectrum of bacterial species, as reported by many researchers [2,4,5,8-16]. Padmavathy and Vijayaraghavan investigated the antibacterial activity of $\mathrm{ZnO}$ nanoparticles with various particle sizes and reported that with a decreasing particle size the antibacterial efficiency of $\mathrm{ZnO}$ nanoparticles increased [5]. In this research, Gram-negative bacteria seemed to be more resistant to $\mathrm{ZnO}$ nanoparticles than Gram-positive bacteria, and the antibacterial activity of $\mathrm{ZnO}$ nanoparticles increased with decreasing particle size and increasing powder concentration. Moreover, the antibacterial effect of $\mathrm{ZnO}$ nanoparticles was time dependent.

$\mathrm{ZnO}$ nanoparticles are not only effective as antimicrobial agents. In addition, they hold unique optical, chemical sensing, semiconducting, electric conductivity, and piezoelectric properties [17], as well as high catalytic and high photochemical activities. $\mathrm{ZnO}$ is attributed with high optical absorption in the UVA and UVB regions (315-400 $\mathrm{nm}$ and $280-315 \mathrm{~nm}$, respectively), and is used as a UV protector in protective clothing, cosmetics and beneficial in antibacterial responses [18].

The current market of protective and medical antibacterial textile is currently limited due to the high cost of such materials. Therefore, innovative technologies for production of antibacterial materials are investigated. As for now, none of them are used in large quantities due to the complexity of developed methods and high price of the products. However, ultrasonic irradiation is an important step in applying antibacterial particles during modification of textile materials.

Antimicrobial modification of polymer materials by nanoparticles is enhanced in an ultrasonic field. Abramova et al. coated the textile using the sol-gel method for the synthesis of the titanium dioxide nanoparticles in combination with zinc oxide nanoparticles from titanyl sulfate and zinc nitrate hexahydrate with the goal to assess the method application feasibility to obtain antibacterial coatings on textile materials [19]. Their resulting textile samples reduced the number of microorganisms of Escherichia coli by more than $99.99 \%$ and achieved an antibacterial activity of more than 1.9 [19] Akhavan and Montazer simultaneously loaded titanium dioxide nanoparticles during their sonosynthesis onto a cotton fabric [20]. In their work, titanium tetra isopropoxide (TTIP) was used as the precursor and ultrasonic irradiation was utilized as a tool for the synthesis of $\mathrm{TiO}_{2}$ at low temperature with an anatase structure, by loading nanoparticles onto the cotton fabric. The results confirmed good self-cleaning and UV-protection properties, and that the sonochemical method had no negative influence on the cotton fabric structure. In contrast, ultrasound used in sonoimmobilization on textile materials like wool enhances homogenous distribution and results in excellent antibacterial/antifungal properties with low negative effects on human dermal fibroblasts [21].

In addition, the mechanical properties of nanocomposite films can be improved by ultrasonic irradiation after the addition of cellulose/silica to the antimicrobial polymer membrane structure [22]. Moreover, the addition of reducing, stabilizing and binding agents such as the natural biopolymer Tragacanth gum can benefit the in situ synthesis of zinc oxide nanoparticles on the cotton fabric. Ultrasonic irradiation leads to the clean and easy synthesis of zinc oxide nanoparticles over a short 
time and at a low temperature [23]. The finished cotton fabric has efficient antimicrobial protection against Staphylococcus aureus, Escherichia coli and Candida albicans, with inhibition zones of $3.3 \pm 0.1$, $3.1 \pm 0.1$ and $3.0 \pm 0.1 \mathrm{~mm}$ [23]. The modification of the morphology of $\mathrm{ZnO}$ nanoparticles, for example, into thorn-like $\mathrm{ZnO}$ nanoparticles, shows even more promising antimicrobial results [24].

Nanomaterial toxicity effects depend on particle composition, size, and shape. The main mechanism of toxicity of nanoparticles is via oxidative species that damage proteins and DNA, as well as the catalytic properties, optical properties, and electrical conductivity of cells. During the investigation of the toxicity of nanoparticles, catalase, glutathione, and superoxide dismutase have been associated with the defense system to oxidative stress, according to Barata and his coworkers [25]. Liu et al. proved that nanoparticles of $\mathrm{ZnO}, \mathrm{CuO}, \mathrm{TiO}_{2}$, and $\mathrm{Au}$ are toxic to the daphnids of Daphnia magna and early life stages of zebrafish [26]. Mostly nanoparticles with diameters of $30 \mathrm{~nm}(\mathrm{ZnO})$ and $20 \mathrm{~nm}\left(\mathrm{TiO}_{2}\right)$ induced more toxicity than larger dimensions $\left(50 \mathrm{~nm} \mathrm{ZnO}\right.$ and $30 \mathrm{~nm} \mathrm{TiO}{ }_{2}$ ) because smaller particles were more likely to enter the cell. The toxicological effects of $\mathrm{ZnO}$ nanoparticles are very important for cellulose materials, which are coming into direct contact with human skin. Therefore, this emphasizes the need for the intense investigation of $\mathrm{ZnO}$ nanoparticles and their effects on living organisms, including microorganisms [27].

Cellulose materials can be functionalized by applying layers of different nanoparticles to their structure. The functionalization of textiles with $\mathrm{ZnO}$ nanostructures enables the production of reinforced textiles resistant to tear and make wearing antibacterial textiles, UV- blocking textiles and other interesting materials possible. In addition to antibacterial properties, anti-odor, self-cleaning and medicinal textiles are made with $\mathrm{ZnO}$. Functionalization can be achieved through different modifications, and the sol-gel process is an important part of them by being a simple, practical and cost-effective approach [28]. Moreover, it enables facile coating by obtaining a homogenous layer on large sample surfaces, the easy control of reaction kinetics, lower sintering temperatures and other advantages [28-30]. The most important advantages of the sol-gel process is the fact that a homogenous, unified and flat coating can be achieved at a mild and low temperature (below $100{ }^{\circ} \mathrm{C}$ ), its flexibility and large surface modification [31].

\section{Experimental}

\subsection{Samples}

Samples used for modification were made of viscose and cellulose polymers (ISO 1833: 2003), with a mass per unit area of $72.26 \mathrm{~g} / \mathrm{m}^{2}$ (EN ISO 2286-2:2008), $0.51 \mathrm{~mm}$ thickness (EN ISO 5084: 2003) and with 54 (50) threads/cm in warp (weft), respectively (EN 1049-2: 2003). All used chemicals were of analytical grade and were utilized without additional purification. The glassware were properly washed, sanitized and autoclaved. $\mathrm{ZnO}$ nanoparticles used for modification of cellulose materials were purchased from Sigma Aldrich (product number 721077, $20 \mathrm{wt} \%$ dispersion of $\mathrm{ZnO}$ nanoparticles in water with certified particle size less than $100 \mathrm{~nm}$ ), and Pt nanoparticles of $3 \mathrm{~nm}$ dispersion in water, product number 773875 .

\subsection{Dip Coating Process}

Cellulose materials were modified with $\mathrm{ZnO}$ nanoparticles by dip-coating methodology using 3-glycidyloxypropyltrimethoxysilane (GLYMO, Sigma Aldrich, Darmstadt, Germany, Europe) as a precursor. The speed of the process was $1 \mathrm{~mm} / \mathrm{s}$. The sols with $\mathrm{ZnO}$ nanoparticles were stirred magnetically and, afterwards, the GLYMO was added, and the process was carried out by ultrasound with different irradiation levels, and at different time intervals, until a homogeneous solution was obtained. Samples were left to gel at room temperature and then dried for $24 \mathrm{~h}$ at room temperature and atmospheric pressure, then at $100{ }^{\circ} \mathrm{C}$ for $60 \mathrm{~min}$. Cellulose-modified products were characterized by thin layer chromatography (TLC), scanning electron microscopy with an EDX detector (SEM-EDX, Tescan Vega, Brno, Czech Republic) and FTIR-ATR (Perkin Elmer, Waltham, MA, USA) spectroscopy. 
The sol-gel process, influenced by numerous parameters such as temperature, time, precursor and $\mathrm{HCl}$ for catalysis, was optimized for all relevant parameters.

In this research, the effect of ultrasonic irradiation power, the concentration of used reagents including nanoparticles, organic precursor and acid, as well as time intervals, on the structure, morphology and antimicrobial activity of cellulose materials modified with zinc oxide nanoparticles using the sol-gel method was investigated.

\subsection{Spectroscopical and Microscopical Characterization}

The structure and the morphology of samples before and after the modification with the $\mathrm{ZnO}$ nanoparticles were recorded under the scanning electronic microscope "TESCAN VEGA TS5136LS" (Tescan Vega company, Brno, Czech Republic) with an EDS detector, which was applied for this characterization of modified cellulose. An SEM microphotograph of the modified antimicrobial cellulose material is presented in Figure 1.

A) Ultrasonically irradiated Dip-coating process

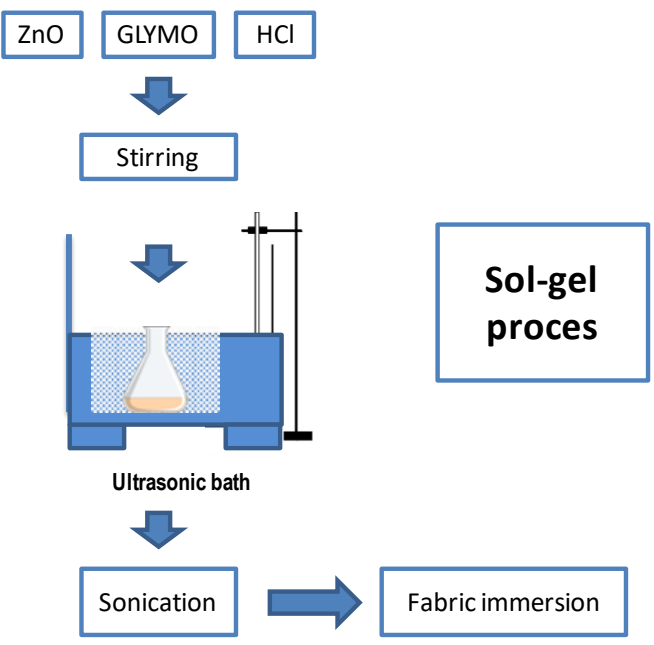

B) Modified antibacterial cellulose material

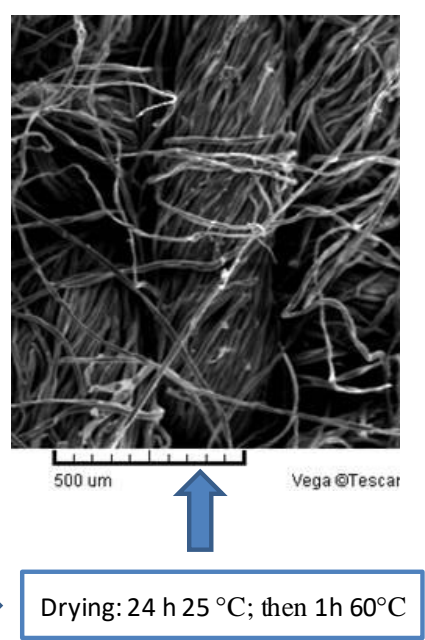

Figure 1. Schematic overview of ultrasonically irradiated dip-coating process with (A) diagram of sonicated sol-gel process and (B) the resulting SEM microphotograph recorded under a magnification of $80 \times$ on the modified antimicrobial cellulose material.

A Fourier transform infrared spectrometer (Spectrum 100 FTIR, Perkin Elmer, Waltham, MA, USA), which applies KBr and Attenuated Total Reflectance (ATR) techniques and enables the recording of spectra of cellulose materials in their solid state, was used to detect the functional groups before and after the modification. The FTIR spectra of samples were recorded at a resolution of $4 \mathrm{~cm}^{-1}$ in the frequency range from 400 to $4000 \mathrm{~cm}^{-1}$ in diffuse reflectance mode. The identification of various functional groups and chemical structures in the $\mathrm{ZnO}-\mathrm{NPs}$ was done by analyzing the absorption of electromagnetic waves at distinctive frequencies and intensities. An average of three scans for each sample was taken for the peak identification. A Nanoparticle Tracking Analyzer (NTA), "Nanosight", was used to record the size and distribution of nanoparticles.

\subsection{Testing of Antimicrobial Activity of Coating with Nanoparticles}

The samples were tested for bactericidal and fungicidal activity by the disc-diffusion method, as well as growth inhibition studies against both Gram-positive (Staphylococcus aureus) and Gram-negative (Escherichia coli) bacteria. In order to assess the effects of ultrasonic irradiation on the antimicrobial effects of modified polymers, the in vitro antimicrobial activity of used colloidal $\mathrm{ZnO}$ nanoparticles for different model microorganisms were investigated by agar well diffusion and serial two-fold 
microdilution assays. After this preliminary step, cellulose materials modified with $\mathrm{ZnO}$ nanoparticles were tested for their antimicrobial properties with the "time-kill" assay. Performed experiments included standard laboratory Gram-positive and Gram-negative bacterial strains including American Type Culture Collection (ATCC) Staphylococcus aureus ATCC 29213 and Escherichia coli ATCC 10536, with additional methicillin-susceptible S. aureus (MSSA MFBF 10663) and methicillin-resistant S. aureus (MRSA MFBF 10679) clinical isolates from the stock-cultures of the Collection of Microorganisms of the Department of Microbiology, Faculty of Pharmacy and Biochemistry, University of Zagreb. All microbial media were purchased from Merck (Darmstadt, Germany) and norofloxacin and gentamicin were purchased from Sigma-Aldrich.

\subsubsection{Agar Well Diffusion Assay}

The agar well diffusion assay was performed according to European Pharmacopoeia, with slight modifications [32]. Inocula were prepared from fresh overnight cultures with physiological saline and adjusted to $0.5 \mathrm{McF}$ arland units (Kisker densitometer, Steinfurt, Germany). After inoculation, sample application to wells $(50 \mu \mathrm{L})$ and preincubation of plates at $+4{ }^{\circ} \mathrm{C}$ for $1 \mathrm{~h}$ followed by incubation at $+37^{\circ} \mathrm{C}$ for $18 \mathrm{~h}$ was performed under aerobic conditions in the dark. After incubation, antimicrobial activity was evaluated by measuring the diameters of zones of growth inhibition $(\mathrm{d}, \mathrm{mm})$ around wells. Gentamicin sulphate and norfloxacin were used for quality control of the method and strain susceptibility. All tests were performed in quintuplicate and results were expressed as the mean.

\subsubsection{Serial Microdilution Broth Assay}

Minimal inhibitory concentrations (MICs) were investigated, guided by the serial microdilution broth assay, according to The European Committee on Antimicrobial Susceptibility Testing guidelines (EUCAST E.Def.5.1), with a major modification by replacing Mueller-Hinton broth with physiological saline in order to avoid the interfering activity of nanosized $\mathrm{ZnO}$ with the diverse protein contents present in the broth [33]. After performing the standard procedure of serial two-fold micro-dilution and incubation at $37^{\circ} \mathrm{C}$ for $18-24 \mathrm{~h}$, the colloidal nature of the nanosized $\mathrm{ZnO}$ and physiological saline as the medium conditioned the subcultivation of $10 \mu \mathrm{L}$ from each dilution of the sample on the surface of tryptic soy agar. Reincubation at $35-37^{\circ} \mathrm{C}$ was then carried out for $18 \mathrm{~h}$ in order to evaluate bacterial viability. Gentamicin sulphate and norfloxacin were used as the positive control, and pure physiological saline was used as the negative control. Minimal inhibitory concentration (MIC) was defined as the lowest concentration of $\mathrm{ZnO}$, which allows no more than $20 \%$ microbial growth in comparison with the negative control. All tests were performed in triplicate and results were expressed as mean values.

\subsection{3. "Time-kill” Assay}

Time-kill methodology was used to investigate the antimicrobial efficiency of the treated materials on MSSA and MRSA. The time-kill assay is a microbiological method that enables the quantification of microbial growth and survival under the influence of a specific sample monitored in time [34]. In the time-kill methodology, treated samples and the negative control (untreated samples) were cut into standard sized $1 \times 1 \mathrm{~cm}$ pieces, inoculated with $100 \mu \mathrm{L}$ of inoculum, incubated at $37^{\circ} \mathrm{C}$ in an orbital shaker and examined at different time intervals (initial contact time and after 1, 3, 6, 12,18 and $24 \mathrm{~h}$ ). After every investigated time point, the sample was transferred in a sterile test tube, which was pre-filled with $1 \mathrm{~mL}$ of physiological saline and mixed for exactly $30 \mathrm{~s} \mathrm{(Vortex} \mathrm{Genius} \mathrm{3,} \mathrm{Ika,}$ Germany). In total, $100 \mu \mathrm{L}$ of the obtained solution was transferred in a new sterile tube, diluted 10 times, and a further 10-fold serial dilution was performed. Aliquots of diluted series of examined sample solutions were spread on tryptic soy agar plates to allow for the counting of bacterial colonies after $24 \mathrm{~h}$ incubation (aerobically at $37^{\circ} \mathrm{C}$, in dark). Colonies of viable bacteria were counted for both bacterial strains treated with the examined sample, as well as for the negative control (untreated 
cellulose fiber), and the results are shown graphically, with $\log 10 \mathrm{CFU} / \mathrm{mL}$ (colony forming units per $\mathrm{ml}$ ) as a function of time (h).

\subsection{Response Surface Methodology Optimization}

In this study, the response surface methodology (RSM) based on Design of Experiment (State Ease version 9.1, State Ease Company, Minneapolis, MN, USA) software was applied to optimize the process of cellulose modification [35,36]. D-optimal design was selected for obtaining optimal results with a minimal number of preliminary experiments $[37,38]$. After the selection of the design, a "candidate set" with selected points was generated.

The selection procedure for the experimental setup reflected the preliminary experiments involving computer-intensive matrix modeling to achieve the highest possible precision of the model. In total, 26 preliminary experiments were designed and conducted, as is shown in Table 1. Initial parameters chosen for modeling were time, temperature, ultrasound irradiation power and concentrations of reagents (GLYMO, $\mathrm{HCl}$ and $\mathrm{ZnO}$ nanoparticles).

Table 1. Investigated parameters used during optimization of dip-coating process by Design of Experiment statistical methodology and calculated recovery angles.

\begin{tabular}{ccccccc}
\hline $\mathbf{N r}$ & $\begin{array}{c}\text { GLYMO, } \\
\mathbf{m L}\end{array}$ & $\begin{array}{c}\mathbf{0 . 1} \mathbf{M ~ H C l}, \\
\mathbf{~} \mathbf{H}\end{array}$ & $\begin{array}{c}\text { ZnO, g/100 } \\
\mathbf{~ m L}\end{array}$ & $\begin{array}{c}\text { Ultrasound, } \\
\mathbf{H z}\end{array}$ & $\begin{array}{c}\text { Time, } \\
\text { min }\end{array}$ & $\begin{array}{c}\text { RECOVERY } \\
\text { ANGLES }\end{array}$ \\
\hline $\mathbf{1}$ & 45.0 & 41.8 & 0.70 & 67.5 & 45.0 & 132.6 \\
$\mathbf{2}$ & 45.0 & 78.2 & 0.70 & 67.5 & 45.0 & 126.6 \\
$\mathbf{3}$ & 45.0 & 60.0 & 0.70 & 67.5 & 45.0 & 117.7 \\
$\mathbf{4}$ & 50.0 & 70.0 & 0.40 & 55.0 & 60.0 & 121.7 \\
$\mathbf{5}$ & 35.9 & 60.0 & 0.70 & 67.5 & 45.0 & 112.8 \\
$\mathbf{6}$ & 40.0 & 70.0 & 1.00 & 55.0 & 60.0 & 130.7 \\
$\mathbf{7}$ & 45.0 & 60.0 & 0.70 & 67.5 & 17.7 & 128.8 \\
$\mathbf{8}$ & 40.0 & 70.0 & 0.40 & 80.0 & 60.0 & 129.3 \\
$\mathbf{9}$ & 45.0 & 60.0 & 0.70 & 44.7 & 45.0 & 136.2 \\
$\mathbf{1 0}$ & 45.0 & 60.0 & 0.15 & 67.5 & 45.0 & 129.2 \\
$\mathbf{1 1}$ & 45.0 & 60.0 & 0.70 & 90.3 & 45.0 & 133.2 \\
$\mathbf{1 2}$ & 45.0 & 60.0 & 0.70 & 67.5 & 45.0 & 128.2 \\
$\mathbf{1 3}$ & 50.0 & 70.0 & 1.00 & 55.0 & 30.0 & 125.5 \\
$\mathbf{1 4}$ & 45.0 & 60.0 & 0.70 & 67.5 & 45.0 & 133.5 \\
$\mathbf{1 5}$ & 40.0 & 50.0 & 0.40 & 55.0 & 30.0 & 130.1 \\
$\mathbf{1 6}$ & 50.0 & 50.0 & 1.00 & 55.0 & 60.0 & 130.6 \\
$\mathbf{1 7}$ & 45.0 & 60.0 & 0.70 & 67.5 & 45.0 & 131.6 \\
$\mathbf{1 8}$ & 45.0 & 60.0 & 0.70 & 67.5 & 72.3 & 126.1 \\
$\mathbf{1 9}$ & 45.0 & 60.0 & 0.70 & 67.5 & 45.0 & 131.3 \\
$\mathbf{2 0}$ & 50.0 & 50.0 & 0.40 & 80.0 & 60.0 & 137.5 \\
$\mathbf{2 1}$ & 40.0 & 70.0 & 1.00 & 80.0 & 30.0 & 138.8 \\
$\mathbf{2 2}$ & 54.1 & 60.0 & 0.70 & 67.5 & 45.0 & 134.6 \\
$\mathbf{2 3}$ & 45.0 & 60.0 & 1.25 & 67.5 & 45.0 & 138.2 \\
$\mathbf{2 4}$ & 40.0 & 50.0 & 1.00 & 80.0 & 60.0 & 138.8 \\
$\mathbf{2 5}$ & 50.0 & 50.0 & 1.00 & 80.0 & 30.0 & 137.5 \\
$\mathbf{2 6}$ & 50.0 & 70.0 & 0.40 & 80.0 & 30.0 & 133.0 \\
\hline & & & & & &
\end{tabular}

\subsection{Tensile Properties}

The elastic behavior of modified polymers was tested according to the norm, HRN EN ISO 22313: 2008 , in which the material is exposed to the bending load at a $180^{\circ}$ angle curve with the load on the press, released, and then the time needed to achieve the sample's original position is measured.

\subsection{Thin-Layer Chromatography}

For preliminary testing, in order to see which metals are present in the sample, thin-layer chromatography was applied. The standard sample solution was spotted on $20 \times 20 \mathrm{~cm}$ TLC cellulose pre-coated plates (Merck, Darmstadt, Germany) by glass capillary. Development was, after the saturation of the chromatographic chamber, carried out in the Camag chromatographic chamber by 
the ascending technique to $8 \mathrm{~cm}$ distance. For the mobile system, acetonitrile-hydrochloric acid-water (72: 25: 23) was chosen. After development, the plates were dried, and exposed to ammonia vapors. The chromatograms with colored spots occurred after $37 \mathrm{~min}$ of the development, and showed the presence of zinc. $R_{F}$ factors for each metal was calculated by using the following calculation:

$$
\mathrm{R}_{\mathrm{F}}=\mathrm{l}_{\mathrm{i}} / \mathrm{l}_{0}
$$

presenting the ration between the distances reached by the sample and the mobile phase. After testing the standard metal solutions, the solutions of samples were investigated in the same way.

\section{Results and Discussion}

Cellulose materials with coatings of metal oxide nanoparticles are excellent antimicrobial agents. In the preparation of new functionalized polymers, sol-gel modification is widely used. This process includes many different parameters, which influence applicable properties, so, in this work, the efficiency of sol-gel modification was enhanced with the concentrated $\mathrm{HCl}$, and a homogenous distribution of nanoparticles in the coating was achieved by ultrasonic homogenization. The surface coating was obtained by precursor 3-glycidyloxypropyltrimethoxysilane (GLYMO), which was characterized by FTIR spectroscopy and a scanning electron microscope equipped with an EDX detector (SEM-EDX). This coating was filled with $\mathrm{ZnO}$ nanoparticles with certified particle sizes less than $100 \mathrm{~nm}$, which were chemically bonded to the cellulose surface in order to obtain antibacterial functionalized cellulose material. The effect of ultrasonic irradiation power (40 to $90 \mathrm{kHz}$ ), the concentration of reagents (nanoparticles, precursor and acids) and time (15 to $72 \mathrm{~min}$ ) were investigated in relation to the structure, morphology and antimicrobial activity of coatings with zinc oxide nanoparticles. The antibacterial effects of colloidal $\mathrm{ZnO}$ nanoparticles were tested against two reference bacterial reference strains (S. aureus and E. coli) and the killing effect of modified cellulose materials with $100 \mathrm{~nm} \mathrm{ZnO}$ nanoparticles was tested against a methicillin-sensitive and a methicillin-resistant strain of $S$. aureus.

\subsection{Spectroscopical, Chromatographical and Microscopical Investigations}

In this investigation, both SEM-EDX and FTIR spectroscopic methods were used to proof the quality of achieved modification of cellulose materials before the antimicrobial testing. SEM-EDX methodology enabled the fast and simple non-destructive investigation of the sample morphology and surface chemical composition [39-41]. The samples were observed under 80× magnification, after a process in which the samples were coated with the $\mathrm{Au} / \mathrm{Pd}$ uniform coating (Figure 1). The size of the colloidally stable $\mathrm{ZnO}$ nanoparticles used in the modification of cellulose materials for antimicrobial testing was investigated and monitored by the Nanoparticle Tracking Analyzer Nanosight, which can determine the concentration of nanoparticles, as well as their distribution in the system. All nanoparticles were $100-120 \mathrm{~nm}$ in size.

Zinc monitored by thin-layer chromatography was determined under the $R_{F}$ value of 0.16 , and could be visualized by the pink color when detected with Alisarin S reagent.

Secondly, the samples were investigated by Fourier-transform infrared spectrometry (Spectrum 100 FTIR, Perkin Elmer, Waltham, MA), which applies KBr and Attenuated Total Reflectance (ATR) techniques and enables the recording of the spectra of cellulose materials in their solid state (Figure 2). FTIR was applied as an excellent technique for the investigation of different solid samples [40], including cellulose samples before and after the modification with nanoparticles. 


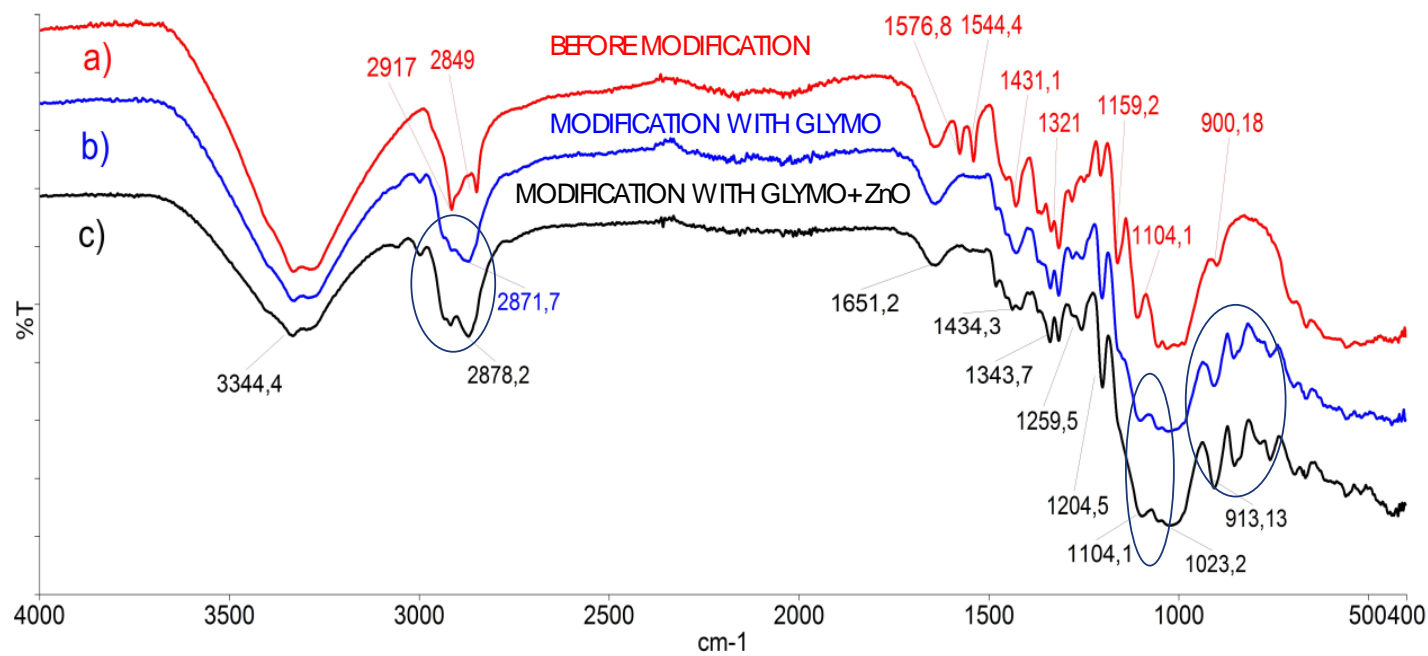

Figure 2. Fourier-transform infrared spectra of cellulose sample before and after the modification with the ZnO nanoparticles: (a) Red line: FTIR-Attenuated Total Reflectance (ATR) spectra of cellulose sample before modification, (b) Blue line: FTIR ATR spectra of cellulose sample after modification with 3-glycidyloxypropyltrimethoxysilane (GLYMO), (c) black line: FTIR ATR spectra of cellulose sample modified with $\mathrm{ZnO}$ nanoparticles and GLYMO, with optimal modification parameters calculated by the Design of Experiment program. Three blue circles define area of the epoxy groups were determined around $\sim 905$ and $911 \mathrm{~cm}^{-1}$, the area around $1100 \mathrm{~cm}^{-1}$ is linked to $\mathrm{Si}-\mathrm{O}$ groups, (particularly Si-O-C and $\mathrm{Si}-\mathrm{O}-\mathrm{Si}$ bridges), and the conversion of metoxy groups in precursor GLYMO are distinguished at $\sim 2870 \mathrm{~cm}^{-1}$.

As can be seen from Figure 2, the lines of samples before and after the sol-gel modification had distinguished differences: the epoxy groups were determined around $\sim 905$ and $911 \mathrm{~cm}^{-1}$, the area around $1100 \mathrm{~cm}^{-1}$ is linked to $\mathrm{Si}-\mathrm{O}$ groups, (particularly $\mathrm{Si}-\mathrm{O}-\mathrm{C}$ and $\mathrm{Si}-\mathrm{O}-\mathrm{Si}$ bridges), and the conversion of metoxy groups in precursor GLYMO are distinguished at $\sim 2870 \mathrm{~cm}^{-1}$. Epoxy groups of GLYMO only react with primary amine and silanol.

The processes of the hydrolysis and crosslinking were monitored and optimized with the goal being to determine favorable conditions for the preparation of the most efficient antimicrobial coating. To improve the application properties, the morphology of the inorganic phase within the hybrid was controlled by changing the hydrolysis conditions of GLYMO and other parameters. It is well known that hybrids from hydrolyzed GLYMO show better mechanical properties in acid hydrolysis, resulting in a very homogeneous hybrid structure, which is the reason why $\mathrm{HCl}$ was used in this research. Moreover, it is emphasized that the presence of hydrochloric acid serves as a catalyst for hydrolysis and decreases the thermal stability of those hybrids. GLYMO reacts in reactions of hydrolysis and condensation, in which alkoxide groups and epoxy rings open. Therefore, it can be concluded that this material is a good starting point for creating hybrid materials with covalent bonds between the organic and inorganic phases.

Moreover, the SEM-EDX results proved that cellulose materials were free of impurities and thus that they were successfully modified. Figure 3 shows an SEM microphotograph of the surface with nanoparticle modification and Figure $3 b$ shows the EDX spectra of this surface. The mapping of the $\mathrm{ZnO}$ nanoparticles on a selected area is shown in Figure 3c. As can be seen from these results, a uniform homogenous coating was created over the sample surface with an equal distribution of $\mathrm{ZnO}$ nanoparticles (Figure 3c). 


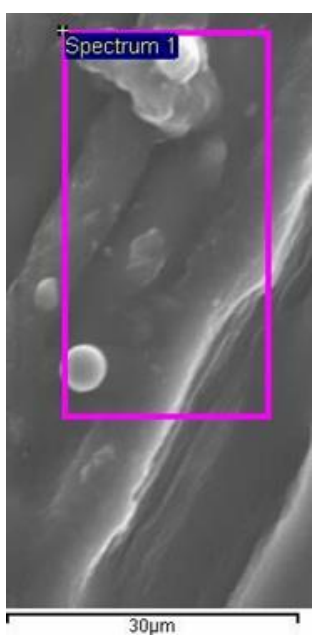

(A)

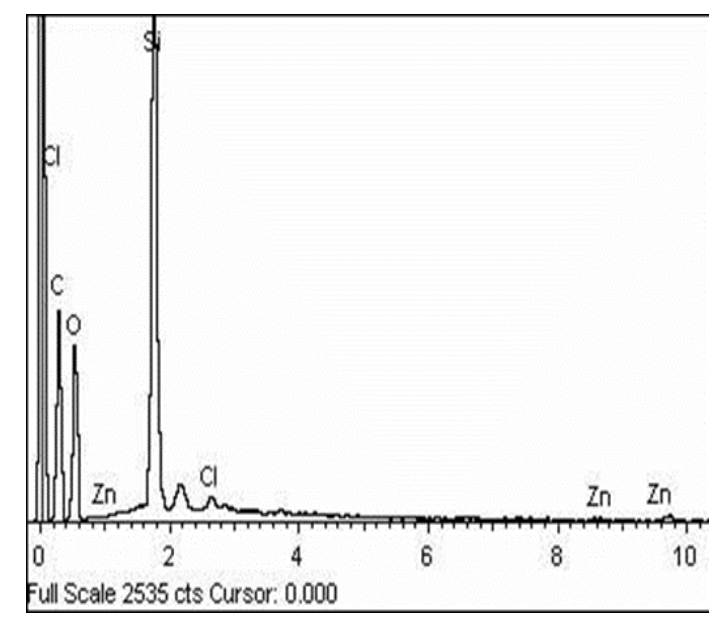

(B)

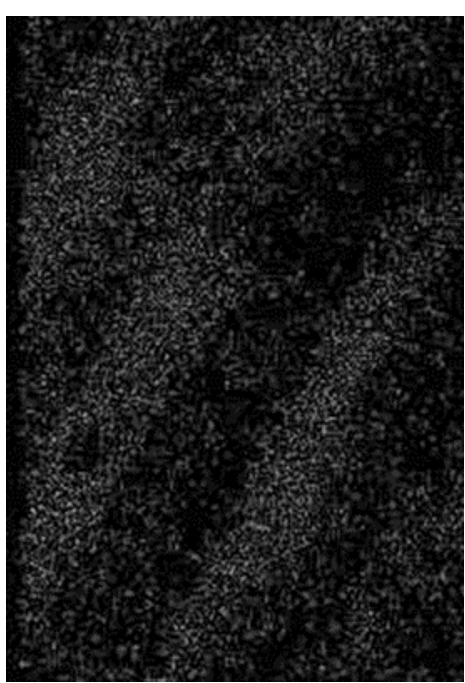

(C)

Figure 3. (A) SEM microphotograph of $\mathrm{ZnO}$ nanoparticle and homogenous coating layer on cellulose materials with specified area used for EDX investigation, The purple square is the area that was scanned for mapping (C); (B) Results of the SEM-EDX investigation with the proof that the cellulose material was successfully modified with the ZnO coating, (C) SEM-EDX mapping was additionally performed on a specified area of the cellulose material in order to detect $\mathrm{ZnO}$ nanoparticles (gray dots on the figure) showing a homogenous coating, as proof of successful modification. Magnification of C was 1000 times.

\subsection{Optimization of Dip-Coating Process through Modeling of Recovery Angle}

For the evaluation of the experimentally obtained results, a mathematical model was obtained. Its response is a function of the tested parameters and, in this investigation, the independent variables were the concentrations of reagents (GLYMO, $\mathrm{HCl}$ and $\mathrm{ZnO}$ nanoparticles), ultrasound irradiation power and time.

Interactions between the independent variables are presented in Figure 4. This figure shows 3D response surface plots for the investigated parameters. The effects of the ultrasonound power are related to a) the concentration of GLYMO, b) the concentration of $\mathrm{HCl}, \mathrm{c}$ ) the concentration of $\mathrm{ZnO}$ nanoparticles and d) the time of the obtained modification.

The 3D response surface condition plots were drawn by State Ease software and they enable the detection of the correlation between particular independent variables.

Figure 4 shows that at higher concentrations of precursor GLYMO and lower concentrations of $\mathrm{HCl}$ acid, the best results are achieved. Accordingly, at lower concentrations of $\mathrm{ZnO}$ and higher ultrasound power in shorter time intervals, higher numbers of nanoparticles were loaded onto the materials. Conversely, a prolonged sonication time and stronger power leads to the less effective loading of nanoparticles on the cellulose material.

This can be interpreted with a hypothesis that cellulose material has a limited surface available for nanoparticles [41]. Aggregated nanoparticles can be easily removed from the cellulose surfaces by bubble collapse during sonication. Moreover, small particles can penetrate into the material and adhere strongly to it, so using more nanoparticles results in more aggregation through prolonged sonication and results in removing aggregates with nanoparticles. In addition, the loading of nanoparticles relies upon both nanoparticle concentration and sonication time [41].

A good relaxation phenomenon is characterized with high values for the recovery angle. Therefore, this is a crucial parameter for medical textiles since it defines the comfort of the material and its softness in the contact with the skin. Since the modification of the surface of cellulosic materials was performed with the goal of making materials that could be used as medicinal textiles, the maximization of the recovery angle was selected as the goal of optimization. Cellulosic materials that were modified in 
26 preliminary experiments were tested for their recovery angles according to the norm EN ISO 22313: 2008. Table 1 shows results that are recalculated as mean values from $n=3$ experiments.

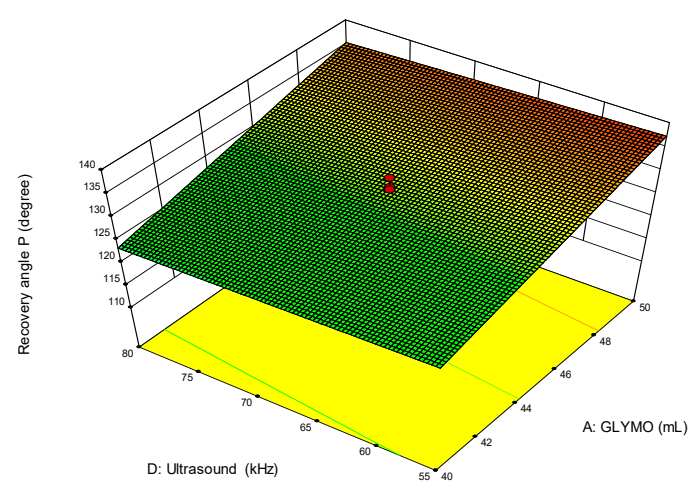

(A)

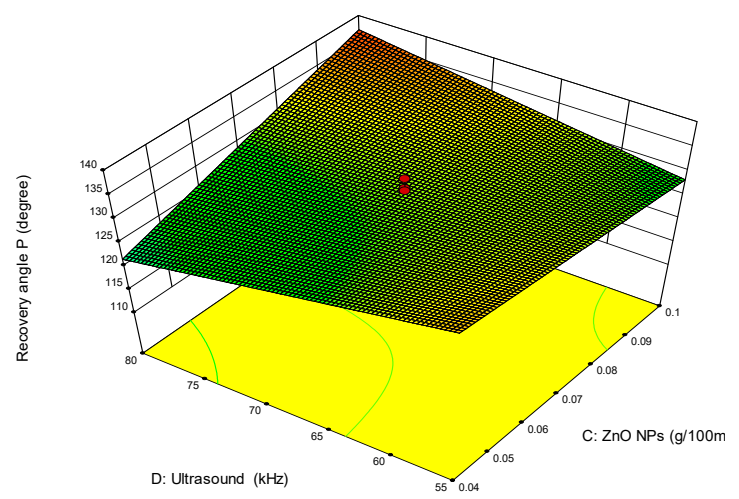

(C)

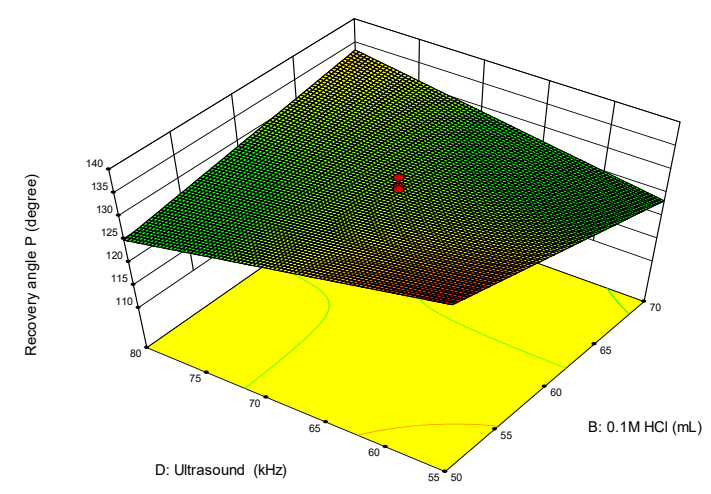

(B)

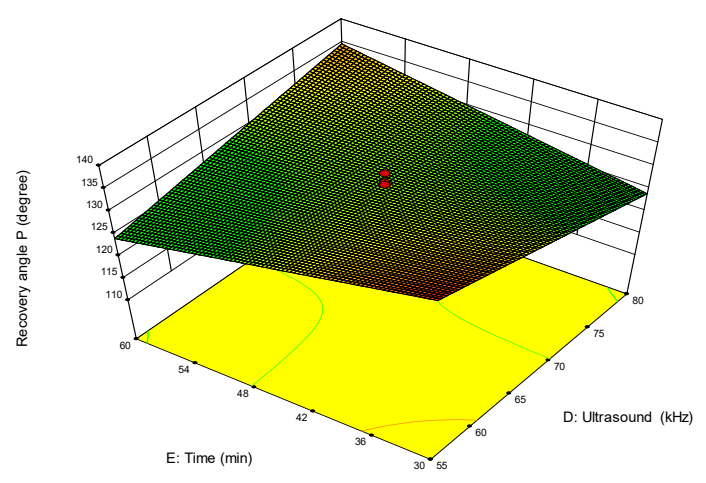

(D)

Figure 4. Three-dimensional response surface plots for investigating parameters: effects of the ultrasonic irradiation and (A) GLYMO, (B) $\mathrm{HCl},(\mathbf{C}) \mathrm{ZnO}$ nanoparticles and (D) time on the obtained modified cellulose.

The results were used for modeling. The obtained model, describing the process with a good level of precision, is as follows:

$$
\begin{gathered}
\text { "Recovery angle" }=108.92+0.34 \mathrm{c}\left(\mathrm{GLYMO}\left(\mathrm{mol} / \mathrm{dm}^{-3}\right)\right)-0.018 \mathrm{c}\left(\mathrm{HCl}\left(\mathrm{mol} / \mathrm{dm}^{-3}\right)\right)+ \\
72.28(\mathrm{~m} / \mathrm{g}(\mathrm{ZnO}))+0.19(\mathrm{Ultrasound} \text { power } / \mathrm{Hz})-0.03(\mathrm{time} / \mathrm{min})
\end{gathered}
$$

To investigate if this model can be used in predicting the response for the investigated parameters and in the optimization of the process of cellulose modification, a comparison of predicted and experimentally obtained values was performed. The results are presented in Table 2.

Table 2. Comparison of predicted and actual values of recovery angles.

\begin{tabular}{ccccccc}
\hline $\begin{array}{c}\text { GLYMO, } \\
\mathbf{m L}\end{array}$ & $\begin{array}{c}\mathbf{0 . 1 M ~ H C l}, \\
\mathbf{m L}\end{array}$ & $\begin{array}{c}\text { ZnO NPs } \\
\mathbf{g} / \mathbf{1 0 0} \mathbf{~ m L}\end{array}$ & $\begin{array}{c}\text { Ultrasound, } \\
\mathbf{H z}\end{array}$ & $\begin{array}{c}\text { Time, } \\
\mathbf{m i n}\end{array}$ & $\begin{array}{c}\text { Predicted } \\
\text { Recovery Angle }\end{array}$ & $\begin{array}{c}\text { Actual } \\
\text { Recovery Angle }\end{array}$ \\
\hline 50.000 & 50.000 & 0.071 & 79.975 & 31.340 & 133.6 & 132.7 \\
50.000 & 50.297 & 0.071 & 80.000 & 30.572 & 135.7 & 135.8 \\
\hline
\end{tabular}

The optimal parameter values for the modification of cellulose were predicted as $50 \mathrm{~mL}$ of GLYMO, $\mathrm{m}(\mathrm{ZnO})=0.071 \mathrm{~g}, 50 \mathrm{~mL}$ of the catalyzer, $\mathrm{HCl}=0.1 \mathrm{~mol} / \mathrm{L}$, and ultrasound $80 \mathrm{kHZ}$ applied for $30.5 \mathrm{~min}$. The predicted values of the parameters were experimentally tested, and the results were compared to predicted values (Table 2). As can be seen from the results, the obtained relative error between 
calculated and predicted values was very low $(0.007-0.670 \%)$. Low values of the coefficient of variation $(\mathrm{CV} \%)$ of the selected model indicate a very good model precision and the very good reliability of the experiments. Therefore, the optimal combination of parameters was used for the preparation of the antibacterial coating prior to the testing of antibacterial strength.

\subsection{Antibacterial Strength of the Cellulose Modified with $\mathrm{ZnO}$ Nanoparticles}

The optimal concentration of $\mathrm{ZnO}$ nanoparticles was prepared and zones of inhibition of bacterial growth and MICs were investigated for E. coli and S. aureus. The results shown in Table 3 reveal stronger antibacterial activity against $S$. aureus compared to $E$. coli in both performed assays (Z.I. $37 \mathrm{~mm}$ vs. $24 \mathrm{~mm}$ and MIC $0.03 \mathrm{ppm}$ vs. MIC $0.76 \mathrm{ppm}$, respectively) [42].

Table 3. Antibacterial activity of colloidal $\mathrm{ZnO}$ nanoparticles.

\begin{tabular}{|c|c|c|c|c|c|c|c|}
\hline \multicolumn{5}{|c|}{ Agar Well Diffusion (Z.I., mm) } & \multicolumn{3}{|c|}{ Microdilution (MIC) } \\
\hline \multirow{2}{*}{ Bacterial Strain } & \multicolumn{2}{|c|}{$\mathrm{ZnO}$} & \multicolumn{2}{|c|}{$\begin{array}{l}\text { Positive Control } \\
(\mu \mathrm{g} / \mathrm{mL})^{* *}\end{array}$} & \multirow{2}{*}{$\underset{\mu \mathrm{ZnO} / \mathrm{mL}}{\stackrel{\mathrm{ZnO}}{ }}$} & \multicolumn{2}{|c|}{$\begin{array}{c}\text { Positive Control } \\
(\mu \mathrm{g} / \mathrm{mL})\end{array}$} \\
\hline & $21 \% *$ & $10 \% *$ & Norfloxacin & Gentamicin & & Norfloxacin & Gentamicin \\
\hline S. aureus ATCC 29213 & 37 & 15 & - & 17 & 0.03 & - & 0.63 \\
\hline E. coli ATCC 10536 & 24 & 0 & 23 & - & 0.76 & 0.02 & - \\
\hline
\end{tabular}

* $21 \%$ is equal to $210000 \mu \mathrm{g} / \mathrm{mL}, 10 \%$ equal to $100000 \mu \mathrm{g} / \mathrm{mL} ;{ }^{* *}$ Norfloxacin and gentamicin stock concentrations = $10 \mu \mathrm{g} / \mathrm{mL} ; "$ "- not performed.

In addition, $\mathrm{ZnO}$ nanoparticles were tested on two strains of S. aureus-MSSA and MRSA. The low MIC value of $3.28 \pm 0.55 \mathrm{ppm}$ for MRSA, alongside the even lower value for the $S$. aureus ATCC strain $(0.03 \pm 0.00 \mathrm{ppm})$, confirmed the potential of $\mathrm{ZnO}$ nanoparticles for further examination in antimicrobial coatings.

The coated cellulose materials were examined and the activity of samples with nanosized $\mathrm{ZnO}$ particles $(100 \mathrm{~nm})$ in combination with significantly smaller nanosized platinum particles $(3 \mathrm{~nm})$ are shown in Figures 5 and 6.

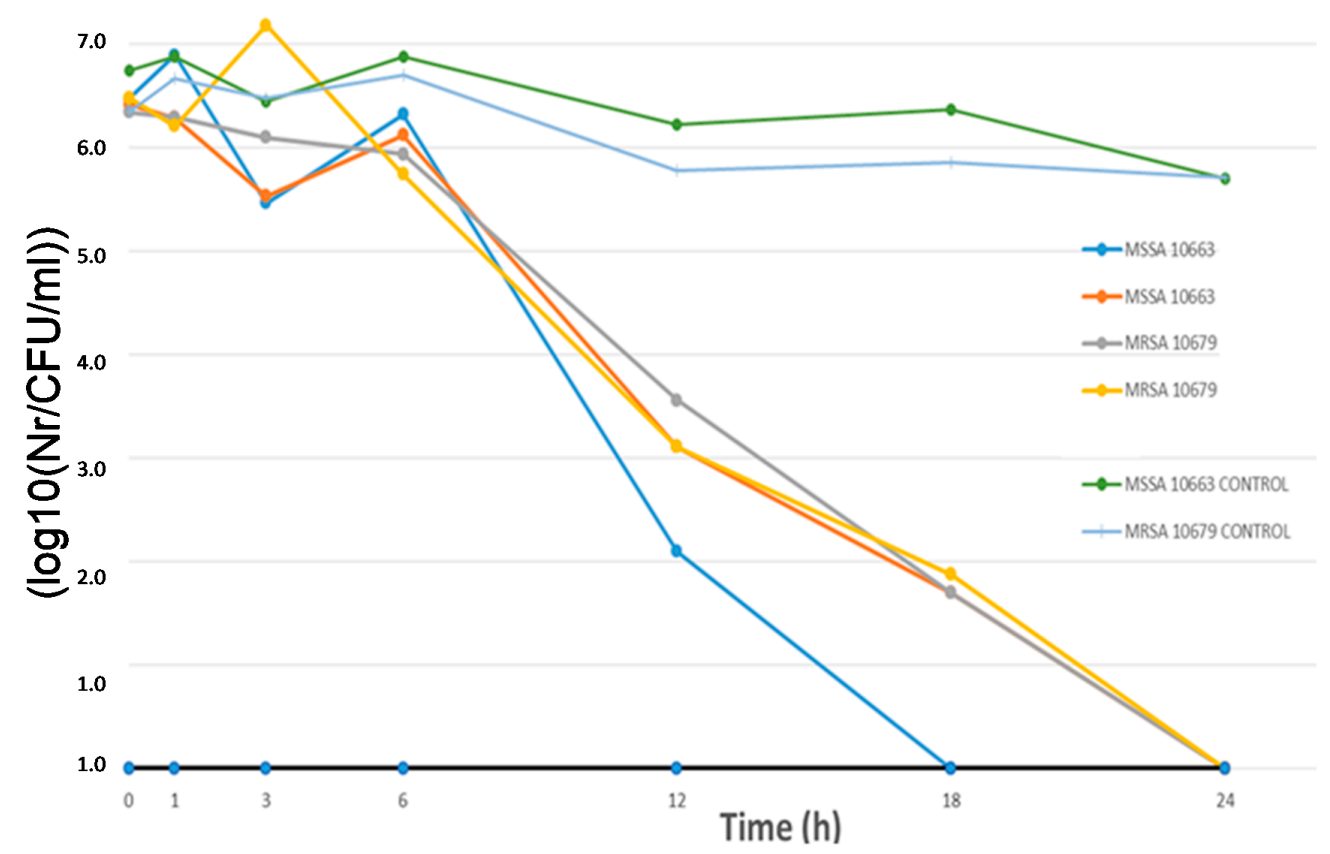

Figure 5. "Time-kill" assay-graphical presentation of antimicrobial efficiency of modified cellulose materials with $100 \mathrm{~nm} \mathrm{ZnO}$ nanoparticles. The effects were achieved in combination with colloidal platinum ( $3 \mathrm{~nm}$ ) against MSSA and MRSA. 


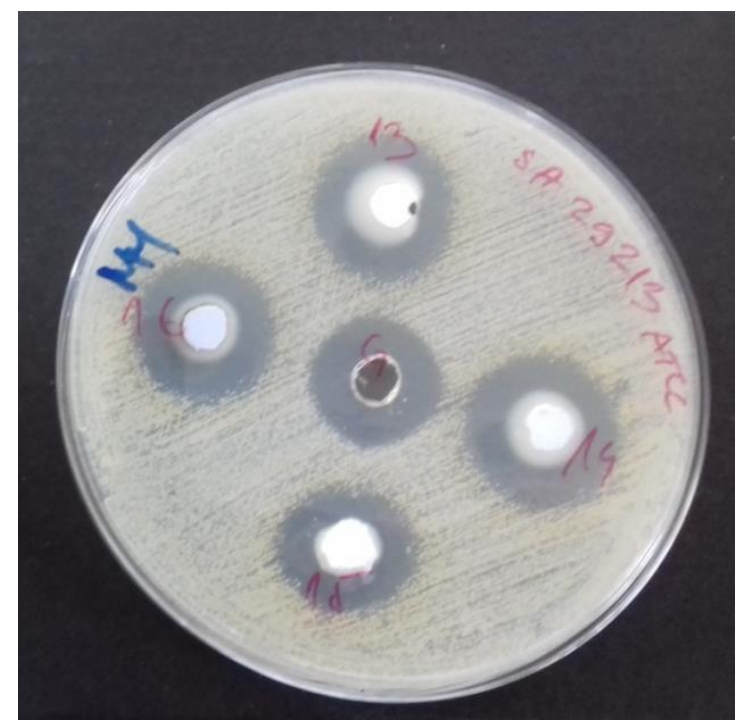

Figure 6. The plate after antimicrobial tests show potent antimicrobial activity against tested microorganisms.

As can be seen from Figure 5, the antibacterial effect starts significantly after $6 \mathrm{~h}$ of exposure to cellulose materials modified with nanoparticles under ultrasonic irradiation compared to controls (untreated cellulose material). Figures 5 and 6 show the results of antimicrobial experiments. All viable bacteria were eliminated after $24 \mathrm{~h}$ for all investigated samples.

This is an excellent result, promising further valuable results in future research within this scientific area. The spread of MRSA can be prevented by the use of disposable gloves, capes and masks, but this is not always feasible. Therefore, new materials need to be developed that are active against microorganisms resistant to antibiotics.

In this research, the effect of process parameters was investigated on the structure, morphology and antimicrobial activity of coatings with zinc oxide nanoparticles. The parameters were varied in their process ranges by ultrasonic irradiation power ( 40 to $90 \mathrm{kHz})$, the concentration of reagents (nanoparticles, precursor and acids) and time (15 to $72 \mathrm{~min}$ ).

Based on the obtained results, it was observed that the amount of nanoparticles on cellulose material depended on the concentration of the reagents, ultrasound irradiation power and the time of the sonication. Other parameters had fewer effects. Moreover, ultrasonic irradiation (power and time) had a synergistic role in terms of the reagent concentration during the modification of the cellulose layer at low temperatures.

\section{Conclusions}

In this research, $\mathrm{ZnO}$ nanoparticles were chemically bonded to the cellulose surface by the sol-gel process in order to obtain an antibacterial functionalized material. The $\mathrm{ZnO}$ nanoparticles were efficiently applied at low temperature and atmospheric pressure, and a homogenous coating was obtained. A prolonged sonication time and stronger power leads to the less effective loading of nanoparticles on the cellulose material, which confirms that ultrasonic irradiation is a vital parameter that is important for obtaining a homogenous, antimicrobial and effective surface.

SEM images and FTIR spectra proved the formation of new chemical bonds and the adhesion of $\mathrm{ZnO}$ nanoparticles on the surface of the material. Antibacterial testing proved that this material is an effective antibacterial surface.

Based on the statistical analysis, the amount of the nanoparticles on cellulose material depends on the concentration of the reagents, ultrasound irradiation power and the time of the sonication. According to the obtained model, the optimal conditions for achieving the most flexible antimicrobial material depend on the concentration of reagents $(\mathrm{ZnO} 0.071 \mathrm{~g}, \mathrm{HCl} 0.1 \mathrm{M})$ and ultrasound irradiation 
$(80 \mathrm{kHz})$. For these conditions, a very low relative error between predicted and experimental values was obtained $(0.007-0.670 \%)$. Therefore, it can be concluded that ultrasonic irradiation (power and time) has a synergistic role in terms of the reagent concentration during the modification of cellulose layers at low temperatures.

Author Contributions: Conceptualization, I.R., I.K.; formal analysis, L.M.P., I.P., M.S.Š. and V.L.B.; Methodology, M.S.Š., I.K. and I.R.; project administration, I.R.; resources, I.R.; software, I.R.; supervision, I.K. and I.R.; writing —original draft, I.R.; writing — review \& editing, I.R. All authors have read and agreed to the published version of the manuscript.

Funding: This research was funded by the Croatian Science Foundation grant number IP-2019-04-1381 (project under title 'Antibacterial coating for biodegradable medicine materials ABBAMEDICA'). Any opinions, findings and conclusions or recommendations expressed in this material are those of the authors and do not necessarily reflect the views of the Croatian Science Foundation.

Conflicts of Interest: The authors declare no conflict of interest.

\section{References}

1. World Health Organization. Antimicrobial Resistance Global Report on Surveillance 2014. Available online: https//www.who.int/drugresistance/documents/surveillancereport/en/ (accessed on 1 January 2020).

2. van Hal, S.J.; Jensen, S.O.; Vaska, V.L.; Espedido, B.A.; Paterson, D.L.; Gosbell, I.B. Predictors of mortality in Staphylococcus aureus Bacteremia. Clin. Microbiol. Rev. 2012, 25, 362-386. [CrossRef] [PubMed]

3. Seil, J.T.; Webster, T.J. Antimicrobial applications of nanotechnology methods and literature. Int. J. Nanomed. 2012, 7, 2767-2781.

4. Azam, A.; Ahmed, A.S.; Oves, M.; Khan, M.S.; Habib, S.S.; Memic, A. Antimicrobial activity of metal oxide nanoparticles against Gram-positive and Gram-negative bacteria a comparative study. Int. J. Nanomed. 2011, 7, 6003-6009. [CrossRef] [PubMed]

5. Padmavathy, N.; Vijayaraghavan, R. Enhanced bioactivity of ZnO nanoparticles-an antimicrobial study. Sci. Technol. Adv. Mater. 2008, 9, 035004. [CrossRef]

6. Saraf, R. Cost effective and monodispersed zinc oxide nanoparticles synthesis. Int. J. Adv. Appl. Sci. 2013, 2, $85-88$.

7. Liu, Q.; Zhang, M.; Fang Zx Rong, X.H. Effect of homogenization and ultrasonication on the physical properties of insoluble wheat bran fibres. J. Sci. Food Agric. 2014, 94, 2547-2554. [CrossRef]

8. Beyth, N.; Houri-Haddad, Y.; Domb, A.; Khan, W.; Hazan, R. Alternative Antimicrobial Approach Nano-Antimicrobial Materials. Complement. Altern. Med. 2015, 2015, 246012. [CrossRef]

9. Dizaj, S.M.; Lotpoura, F.; Barzegar-Jalali, M.; Zarrintana, M.H.; Adibkiab, K. Antimicrobial activity of the metals and metal oxide nanoparticles. Mater. Sci. Eng. C 2014, 44, 278-284. [CrossRef]

10. Emami-Karvani, Z.; Chehrazi, P. Antibacterial activity of $\mathrm{ZnO}$ nanoparticle on gram-positive bacteria. Afr. J. Microbiol. Res. 2011, 5, 1368-1373.

11. Rasmussen, J.W.; Martinez, E.; Louka, P.; Wingett, D.G. Zinc oxide nanoparticles for selective destruction of tumor cells and potential for drug delivery applications. Expert Opin. Drug Deliv. 2010, 7, 1063-1077. [CrossRef]

12. Brayner, R.; Ferrari-Iliou, R.; Brivois, N.; Djediat, S.; Benedetti, M.F.; Fievet, F. Toxicological impact studies based on Escherichia coli bacteria in ultrafine $\mathrm{ZnO}$ nanoparticles colloidal medium. Nano Lett. 2006, 6, 866-870. [CrossRef] [PubMed]

13. Jones, N.; Ray, B.; Ranjit, K.T.; Manna, A.C. Antibacterial activity of $\mathrm{ZnO}$ nanoparticle suspensions on a broad spectrum of microorganisms. FEMS Microbiol. Lett. 2008, 279, 71-76. [CrossRef] [PubMed]

14. Jalal, R.; Goharshadi, E.K.; Abareshi, M.; Moosavi, M.; Yousefi, A.; Nancarrow, P. ZnO nanofluids: Green synthesis, characterization. Mater. Chem. Phys. 2008, 121, 198-201. [CrossRef]

15. Raghupathi, K.R.; Koodali, R.T.; Manna, A.C. Size-dependent bacterial growth inhibition and mechanism of antibacterial activity of zinc oxide nanoparticles. Langmuir 2011, 27, 4020-4028. [CrossRef]

16. Xie, Y.; He, Y.; Irwin, P.L.; Jin, T.; Shi, X. Combined Fluxomics and Transcriptomics Analysis of Glucose Catabolism via a Partially Cyclic Pentose Phosphate Pathway in Gluconobacter oxydans 621H. Appl. Environ. Microbiol. 2011, 77, 2325-2331. [CrossRef] 
17. Fan, Z.; Lu, J.G. Zinc oxide nanostructures: Synthesis and properties. J. Nanosci. Nanotechnol. 2005, 5, 1561-1573. [CrossRef]

18. Song, Z.; Kelf, T.A.; Sanchez, W.H.; Roberts, M.S.; Ricka, J.; Frenz, M.; Zvyagin, A.V. Characterization of optical properties of $\mathrm{ZnO}$ nanoparticles for quantitative imaging of transdermal transport. Biomed. Opt. Express 2011, 2, 3321-3333. [CrossRef]

19. Abramova, A.V.; Abramova, V.O.; Bayazitova, V.M.; Voitova, Y.; Straumal, E.A.; Lermontov, S.A.; Cherdyntseva, T.A.; Braeutigam, P.; Weiße, M.; Günther, K. A sol-gel method for applying nanosized antibacterial particles to the surfaceof textile materials in an ultrasonic field. Ultrason. Sonochem. 2020, 60, 104788. [CrossRef]

20. Akhavan, F.; Majid Montazer, S. In situ sonosynthesis of nano TiO2 on cotton fabric. Ultrason. Sonochem. 2014, 21, 681-691. [CrossRef]

21. Behzadnia, A.; Montazer, M.; MahmoudiRad, M. In situ photo sonosynthesis and characterize nonmetal/metal dual doped honeycomb-like $\mathrm{ZnO}$ nanocomposites on wool fabric. Ultrason. Sonochem. 2015, 27, 200-209. [CrossRef]

22. Ahmadizadegan, H.; Esmaielzadeha, S.; Ranjbara, M.; Marzban, Z.; Ghavas, F. Synthesis and characterization of polyester bionanocomposite membrane with ultrasonic irradiation process for gas permeation and antibacterial activity. Ultrason. Sonochem. 2018, 41, 538-550. [CrossRef]

23. Ghayempour, S.; Montazer, M. Ultrasound irradiation based in-situ synthesis of star-like Tragacanth gum/zinc oxide nanoparticles on cotton fabric. Ultrason. Sonochem. 2017, 34, 458-465. [CrossRef]

24. Khan, M.F.; Ansari, A.H.; Hameedullah, M.; Ahmad, E.; Husain, F.M.; Zia, Q.; Baig, U.; Zaheer, M.R.; Alam, M.M.; Khan, A.M.; et al. Sol-gel synthesis of thorn-like ZnO nanoparticles endorsing mechanical stirring effect and their antimicrobial activities Potential role as nano-antibiotics. Nat. Sci. Rep. 2016, 6, 27689. [CrossRef]

25. Barata, C.; Varo, I.; Navarro, J.C.; Arun, S.; Porte, C. Antioxidant enzyme activities and lipid peroxidation in the freshwater cladoceran Daphnia magna exposed to redox cycling compounds. Toxicol. Pharmacol. 2005, 140, 175-186. [CrossRef]

26. Liu, J.; Fan, D.; Wang, L.; Shi, L.; Ding, J.; Chen, Y.; Shen, S. Effects of ZnO, CuO, Au, and TiO2 nanoparticles on Daphnia magna and early life stages of zebrafish danio rerio. Env. Protect. Eng. 2014, 40, 139-1491.

27. Seabra, A.B.; Durán, N. Nanotoxicology of Metal Oxide Nanoparticles. Metals 2015, 5, 934-975. [CrossRef]

28. Wang, N.; Magdassi, S.; Madnler, D.; Long, Y. Simple sol-gel process and one-step annealing of vanadium dioxide thin films: Synthesis and thermochromic properties. Thin Solid Film. 2013, 534, 594-598. [CrossRef]

29. Yadav, A.; Prasad, V.; Kathe, A.A.; Raj, S.; Yadav, D.; Sundaramoorthy, C.; Vigneshwaran, N. Functional finishing in cotton fabrics using zinc oxide nanoparticles. Bull. Mater. Sci. 2006, 29, 641-645. [CrossRef]

30. Vigneshwaran, N.; Kumar, S.; Kathe, A.A.; Varadarajan, P.V.; Prasad, V. Functional finishing of cotton fabrics using zinc oxide soluble starch nanocomposites. Nanotechnology 2006, 17, 5087-5095. [CrossRef]

31. Rezić, I. Cellulosic fibers-biosorptive materials and indicators of heavy metals pollution. Microchem. J. 2013, 107, 63-69. [CrossRef]

32. Council of Europe; European Pharmacopoeia Commission. European Pharmacopoeia, 5th ed.; Council of Europe: Strasbourg, France, 2005; pp. 188-191.

33. European Committee for Antimicrobial Susceptibility Testing (EUCAST) of the European Society for Clinical Microbiology and Infectious Diseases (ESCMID). EUCAST Discussion Document E.Def.5.1. Clin. Microbiol. Infec. 2003, 9, 1-7.

34. Peran, J.; Ercegović Ražić, S.; Kosalec, I.; Ziberi, F. Antimicrobial Effectiveness of Cellulose based Fabrics treated with Silver Nitrate Solution using Plasma Processes. Tekstilec 2017, 60, 247-253. [CrossRef]

35. Rezić, I. Optimization of ultrasonic extraction of 23 elements from cotton. Ultrason. Sonochem. 2009, 16, 63-69. [CrossRef]

36. Rolich, T.; Rezić, I.; Ćurković, L. Estimation of Steel Guitar Strings Corrosion by Artificial Neural Network. Corr. Sci. 2010, 52, 996-1002. [CrossRef]

37. Rezić, I.; Steffan, I. ICP-OES determination of metals present in textile materials. Microchem. J. 2007, 85, 46-51. [CrossRef]

38. Rezić, I.; Ćurković, L.; Ujević, M. Simple methods for characterization of metals in historical textile threads. Talanta 2010, 82, 237-244. [CrossRef] 
39. Rezić, I.; Špehar, M.; Jakovljević, S. Characterization of Ag and Au nanolayers on Cu alloys by TLC, SEM-EDS, and ICP-OES. Mater. Corr. 2017, 68, 560-565. [CrossRef]

40. Rezić, I.; Zeiner, M.; Steffan, I. Determination of 28 selected elements in textiles by axially viewed inductively coupled plasma optical emission spectrometry. Talanta 2011, 83, 865-871. [CrossRef]

41. Reza Mahdavi, S.; Talesh, T.A. The effect of ultrasonic irradiation on the structure, morphology and photocatalytic performance of $\mathrm{ZnO}$ nanoparticles by sol-gel method. Ultrason. Sonochem. 2017, 39, 504-510. [CrossRef]

42. Pokrovac, I. Antimicrobial Effect of Colloidal Nanoparticles of Metals and Metal Oxides on MSSA and MRSA. Ph.D. Thesis, Faculty of Phamacy and Biochemistry, University of Zagreb, Zagreb, Croatia, 2018.

(C) 2020 by the authors. Licensee MDPI, Basel, Switzerland. This article is an open access article distributed under the terms and conditions of the Creative Commons Attribution (CC BY) license (http://creativecommons.org/licenses/by/4.0/). 